\title{
The Effects of Horseback Riding Simulator Exercise on Postural Balance of Chronic Stroke Patients
}

\author{
Jungseo Park, PhD, PT ${ }^{1}$, Sangyong Lee, PhD, PT ${ }^{1)}$, Jiyeun Lee, PhD, PT $^{2}$, \\ DAeHeE LeE, PhD, $\mathrm{PT}^{1)^{*}}$ \\ 1) Department of Physical Therapy, Youngdong University: 12 Youngdong-eup, Youngdong-gun, \\ Chungbuk 370-701, Republic of Korea. TEL: +82 43-740-1402, FAX: +82 43-740-1109 \\ 2) Department of Physical Therapy, Andong Science College
}

\begin{abstract}
Purpose] The aim of this study was to examine the effects of horseback riding simulator exercise on postural balance of chronic stroke patients. [Subjects] A total of 67 stroke patients were assigned either to a horseback riding simulator exercise group (HEG, $n=34$ ) or a mat exercise group (MEG, $n=33$ ). [Methods] The subjects exercised three times per week for 8 weeks. Static balance ability was determined by eyes open balance (EOB) and eyes closed balance (ECB), which was measured using a Kinesthetic Ability Trainer Balance system. Dynamic balance was evaluated using the Berg balance scale (BBS). [Results] EOB and ECB significantly decreased and BBS had significantly increased after the intervention in the HEG and the MEG, and ECB decreased and BBS increased significantly more in the HEG than in the MEG. [Conclusion] Horseback riding simulator exercise is more effective than mat exercise for improving the ECB and BBS of stroke patients.

Key words: Horseback riding simulator exercise, Postural balance, Stroke
\end{abstract}

(This article was submitted Mar. 26, 2013, and was accepted May 4, 2013)

\section{INTRODUCTION}

Patients with postural adjustment disorder have impaired balance and posture. In these patients, abnormal delivery of sensory information greatly influences postural sway and muscle activity, causing disability in activities of daily living and interfering with treatment interventions ${ }^{1)}$.

Diverse rehabilitation programs are available for functional improvement and balance recovery for hemiplegic patients. Among these, horseback riding is a treatment that focuses on three areas: physical rehabilitation, psychological treatment, and the development of social skills. The treatment uses kinesociological movement and different walking patterns such as walk, trot, and riding trot, and nature-friendly characteristics. Physical therapy and psychological treatment approaches are employed to correct the horseback rider's posture and to improve the function of the tendons, ligaments, the cardiopulmonary system, and blood circulation $^{2}$. However, horseback riding therapy itself presents some difficulties as a treatment due to location, costs, and risks. One solution to these difficulties is the horseback riding simulator, which allows simulated horseback riding in a fixed space, and this exercise is possible anytime.

And riding on a simulator assists A horseback riding simulator simulates the rhythmic movement of a horse, the development of equilibrium, flexibility, and whole-body muscles while improving the balance and postural adjustment normal and disabled people ${ }^{3,4)}$. Studies of proprio-

${ }^{*}$ To whom correspondence should be addressed. E-mail:bobath99@hanmail.net ceptive neuromuscular facilitation, Bobath, sling, and ball exercises have examined improvements in the postural balance of stroke patients, but research on the effects of horseback riding simulators is lacking. The aim of the present study was, therefore, to examine the potential benefits of exercise using a horseback riding simulator on the postural balance of chronic stroke patients.

\section{SUBJECTS AND METHODS}

This experiment included 67 stroke patients hospitalized at D hospital in Daejeon, Korea. All subjects read and signed consent forms, in accordance with the ethical standards of the Declaration of Helsinki. The possibility of natural recovery was minimized by selecting only patients whose onset of stroke was at least 6 months prior to the experiment. No patient had diabetes, heart disease, or orthopedic problems and their Korea-mental mini state examination score was 24 or higher. The subjects were able to walk independently for more than 15 minutes. All subjects listened to an explanation of the purpose of this study and exercise method and voluntarily participated in the experiment.

They were able to maintain a standing position independently for more than 30 seconds and could walk in doors continuously for more than $30 \mathrm{~m}$ independently. Also, they had no problems with walking due to orthopedic surgery or impairment, a Modified Ashworth Scale stiffness 2 or less and a lower extremity muscle strength measured as $\mathrm{F}$ or higher in the Manual Muscle Test.

The subjects were divided into a horseback riding simu- 
Table 1. The mat exercise program

\begin{tabular}{cl}
\hline Program & \\
\hline & Trunk Stabilization Exercise Using the Upper Extremities \\
& - Place a square support below the knee joints in a supine position so that the hip joints and the knee joints \\
are at $90^{\circ}$. The therapist holds both of the patient's hands and the patient raises the trunk and the head. \\
Trunk Stabilization Exercise Using the Pelvis
\end{tabular}

lator exercise group (HEG, $\mathrm{n}=34,18$ males and 16 females) and a mat exercise group (MEG, $n=33,18$ males and 15 females). The subjects' average age, height, and weight were $56.09 \pm 7.22$ years old, $166.05 \pm 7.47 \mathrm{~cm}$, and $62.91 \pm 7.93$ $\mathrm{Kg}$, respectively, for the HEG, and $51.55 \pm 8.27$ years old, $169.55 \pm 8.40 \mathrm{~cm}$, and $67.05 \pm 8.38 \mathrm{Kg}$, respectively, for the MEG.

Stroke was the result of cerebral infarction in 15 subjects and cerebral hemorrhage in 19 subjects in the HEG, and cerebral infarction in 16 subjects and cerebral hemorrhage in 17 subjects in the MEG. The onset of stroke was between 7 and 12 months prior to the experiment in 19 patients, and more than 15 months prior in 15 subjects in the HEG. In the MEG, the onset of stroke was between 7 and 12 months prior to the experiment in 20 patients and more than 13 months prior in 13 patients. Both groups received exercise treatment three times per week for 8 weeks and received ordinary physical therapy 6 times per week. A physical therapist with more than 10 years of clinical experience administered the exercise programs.

The HEG used a horseback riding simulator (FORTIS, Korea) with a shape and size similar to those of a real horse (FORTIS, Korea). The simulator had 100 different exercise programs. Since the subjects were patients, course number 71 was selected as it did not include abrupt rhythm and had a comfortable up and down and forward and backward rhythmic movement (the distance between up and down was 52 $\mathrm{m} / \mathrm{min}$, the distance between forward and backward was 39 $\mathrm{m} / \mathrm{min}$, the number of up and down rhythmic movements was 90 to 100 times, the number of forward and backward rhythmic movements was 90 to 100 times, and the rhythm distance was $65 \mathrm{~m} / \mathrm{min}$ ). Course number 74 was also selected as it had a large up and down and forward and backward rhythmic movement, which has a good exercise effect on the neck, shoulders, trunk, abdomen, thighs, and legs (distance between up and down was $73 \mathrm{~m} / \mathrm{min}$, distance between forward and backward was $40 \mathrm{~m} / \mathrm{min}$, the number of up and down rhythmic movements was 95 to 105 times, the number of forward and backward rhythmic movements was 95 to 105 times, and the rhythm distance was $98 \mathrm{~m} /$ $\mathrm{min})$. The exercise was administered for a total of $35 \mathrm{~min}$ utes, three times per week. Each course was administered for 15 minutes and the subjects rested for five minutes after a course. The exercise speed was set at a medium speed $(50 \%)$, which was not fast when compared to the designated rhythmic speeds of the horseback riding simulator. The risk of falling was minimized by equipping the subjects with an automatic stop device.

The MEG performed a trunk stabilization exercise using a mat for 35 minutes (Table 1). The trunk stabilization exercises were performed using the lumbar spinal stabilization exercise methods developed by Norris ${ }^{5)}$ and Richardson and Jull ${ }^{6}$. The exercise session lasted 35 minutes in total, and warm-up and cool-down exercises were performed for five minutes at the beginning and the end of the exercises, respectively. Programs 1 through 3 were repeated 10 times per set and a total of three sets were completed.

Static balance was measured using a Kinesthetic Ability Trainer (KAT) Balance system (KAT 2000 Breg Inc., USA) and the center of pressure sway was recorded The moving platform of the KAT Balance System is supported at the central point on a small pivot. The stability of the plate is regulated by an air pressure cushion between the platform and the floor. When the cushion is inflated, the platform is stabilized, and when the cushion is deflated, the platform becomes very unstable. A tilt sensor installed in front of the platform records the degree of tilt of the platform from the reference point at a rate of 18.2 times per second on a computer. In this experiment, the distance between the center of the plate and the subjects' center of pressure sway was measured in each test to calculate the Balance Index (BI). The BI is an index of a subject's ability to maintain his or her body close to the central point of the platform; so that a low BI score indicates a better balance sense. The subjects maintained a distance of $5-6 \mathrm{~cm}$ between their heels and stood comfortably on the moving platform. Eyes open balance (EOB) and eyes closed balance (ECB) were measured three times for 30 seconds each time and the average values were calculated. Dynamic balance prior to and after the intervention was evaluated using the Berg balance scale (BBS).

The data were statistically processed using SPSS 12.0 for Windows. The paired t-test was used to examine within group changes after the intervention and the independent $\mathrm{t}$ test was employed to examine between-group changes. The significance level was chosen as at $\alpha=0.05$.

\section{RESULTS}

According to the result of this study, EOB and ECB significantly decreased and BBS had significantly increased after the intervention in both the HEG and the MEG $(p<0.05)$. 
Table 2. Comparison between the groups in terms of balance ability

\begin{tabular}{cccc}
\hline Parameter & Group & Pre & Post \\
\hline \multirow{2}{*}{ EOB (BI) } & HEG $^{*}$ & $559.97 \pm 107.76$ & $551.29 \pm 107.82$ \\
& MEG $^{*}$ & $565.61 \pm 123.62$ & $552.61 \pm 95.18$ \\
ECB (BI) & HEG $^{*}$ & $1,412.29 \pm 230.40$ & $1,274.20 \pm 152.62^{\dagger}$ \\
& MEG $^{*}$ & $1,453.82 \pm 195.33$ & $1,375.97 \pm 179.87$ \\
BBS (score) & HEG $^{*}$ & $36.86 \pm 3.63$ & $42.27 \pm 4.85^{\dagger}$ \\
& MEG $^{*}$ & $37.74 \pm 3.75$ & $40.91 \pm 3.14$ \\
\hline
\end{tabular}

EOB: eyes open balance, ECB: eyes closed balance, BBS: Berg Balance Scale, HEG: horse riding simulator exercise group, MEG: mat exercise group, ${ }^{*}$ paired t-test, ${ }^{\dagger}:$ independent sample t-test, ${ }^{*}{ }^{*}: \mathrm{p}<0.05$

In the comparison of the groups after the intervention, ECB decreased and BBS increased significantly more in the HEG than in the MEG $(\mathrm{p}<0.05)$. There was no significant difference in EOB between the groups $(\mathrm{p}>0.05)$ (Table 2).

\section{DISCUSSION}

Factors that are related to stroke patients' gait include their direction perception, standing balance, and voluntary adjustment of the affected side lower extremity, as well as their sense of joint position and the existence or non-existence of joint contracture ${ }^{7}$ )

Lee and Jeong ${ }^{8)}$ reported that when 20 normal adult female students performed horseback riding simulator exercises, the muscle strengths in their thighs and waists were greatly improved. Therefore, since horseback riding simulator exercises improve the muscle strengths in the thigh and lumbar regions, as well as trunk stabilization, the aim of the present study was to examine the effects of horseback riding simulator exercises on the balance ability of stroke patients.

Devienne and Guezennec ${ }^{9)}$ in a study of 20 normal females, noted that horseback riding exercise increased the strength of their knee flexor and the quadriceps femoris muscles. Quint and Toomey ${ }^{10)}$ observed that horseback riding significantly increased the range of forward and backward passive tilt, of a study on 13 children with cerebral palsy. $\mathrm{Choo}^{11)}$ conducted a horseback riding program for children with cerebral palsy for 3 months and reported positive influences on their static and dynamic equilibrium.

Back et al. ${ }^{12)}$ noted that 40 subjects who exercised on a horseback riding simulator had greater increases in the strength of the biceps brachii, transverse abdominis, abdominal oblique, and adductor longus muscles than when they jogged. Lee and Jeong ${ }^{13)}$ reported that horseback simulator exercise increased muscle strengths in the femoral and the lumbar areas of 20 normal female students. Cho et al. ${ }^{14)}$ noted that horseback riding simulator exercise was effective at improving postural balance ability and proprioceptive sense in a study of 30 normal adults. Kuczyński and Słonka ${ }^{15)}$ conducted horseback riding simulator exercise for 25 cerebral palsy children for 12 weeks, and observed a significant improvement in their left and right balance ability.

The balance ability test administered in the present study showed that balance ability after the intervention had improved in both the HEG and MEG, which indicates that both horseback riding and mat exercises are effective at improving postural balance. However, greater improvements after the exercise were observed in the HEG than in the MEG in ECB and BBS. This finding is consistent with the results reported by Hammer et al. ${ }^{6}$ ) who conducted horseback riding simulator exercise for 11 multiple sclerosis patients and observed improvements in their BBS. Similarly, Beinotti et al. ${ }^{7)}$ conducted horseback riding exercise for 20 stroke patients and observed enhancement of their gait and balance abilities. Cho et al. ${ }^{4}$ reported that horseback riding simulator exercises were effective at improving postural balance ability and proprioceptive sense, while Nashner and Peter ${ }^{18)}$ reported that proprioceptive sense-improving exercises elicited a larger improvement in postural sway when the eyes were closed. In the present study, ECB showed significant differences between the groups after the intervention, indicating HEG's proprioceptive senses improved more than MEG's proprioceptive senses; whereas, EOB did not show a significant difference. When horseback riding simulator exercise is performed by chronic stroke patients, increases in the major muscles of the upper and lower extremities and trunk, and improvements in proprioceptive sense ovserved, indicating that the subjects are better able to maintain their balance and equilibrium.

Horseback riding rehabilitation is one of many diverse treatment methods for patients with neurological damage and utilizes the gait of a horse. The horse's rhythmic movement stimulates the patients and aids them to improve posture and balance, and has a treatment effects that include reduced muscle tone, improved trunk adjustment, and enhanced equilibrium responses and autonomic reflexes. However, horses are costly and horseback riding is a sport that is not easily accessible to most ordinary people. In addition, stroke patients are less likely to have an opportunity to do this sport. Horseback riding lacks recognition as a form of rehabilitation, facilities for horseback riding rehabilitation, and professional therapists. However, a horseback riding simulator exercise that mimics movements of a horse can be used as a therapeutic substitute for functional improvement of a patients' balance ability.

The limitations of the present study are that the number of subjects was too small to allow generalization of the results, and no follow-up evaluation was conducted to determine the long-term effects of horseback riding simulator exercise. In addition, muscle strength, rigidity, senses and gait ability were not examined prior to and after the exer- 
cise. Therefore, further research is needed on the effects of horseback riding exercise on muscle activities of the trunk and the lower extremities of stroke patients.

\section{REFERENCES}

1) Hlavacka F, Horak FB: Somatosensory influence on postural response to galvanic vestibular stimulation. Physiol Res, 2006, 55: S121-S127. [Medline]

2) Lee JY: North American overview on therapeutic riding. Suwon Univer sity, Theses collection, 1999, 17: 557-564.

3) Sterba JA: Does horseback riding therapy or therapist-directed hippotherapy rehabilitate children with cerebral palsy? Dev Med Child Neurol, 2007, 49: 68-73. [Medline] [CrossRef]

4) Janura $M$, Peham $C$, Dvorakova $T$, et al.: An assessment of the pressure distribution exerted by a rider on the back of a horse during hippotherapy. Hum Mov Sci, 2009, 28: 387-393. [Medline] [CrossRef]

5) Norris CM: Spinal stabilization: 5. An exercise programme to enhance lumbar stabilisation. Physiotherapy, 1995, 81: 138-146. [CrossRef]

6) Richardson CA, Jull GA: Muscle control-pain control. What exercises would you prescribe? Man Ther, 1995. 1: 2-10. [Medline] [CrossRef]

7) Anderson TP: Rehabilitation of patient with complete stroke: Krusen's handbook of physical medicine and rehabilitation, 4th ed. Philadelphia: WB Saunder's Company. 1990, pp 656-678.

8) Lee SK, Jeong JH: The effects of indoor horseback-riding exercise on health-related fitness, serum lipids, and defecation satisfaction of female collegiate students. Korea Sport Research, 2005, 16: 153-160.

9) Devienne MF, Guezennec CY: Energy expenditure of horse riding. Eur J
Appl Physiol, 2000, 82: 499-503. [Medline] [CrossRef]

10) Quint C, Toomey M: Powered saddle and pelvic mobility: an investigation into the effects on pelvic mobility of children with cerebral palsy of a powered saddle which imitates the movements of a walking horse. Physiotherapy, 1998, 84: 376-384. [CrossRef]

11) Choo HK: The effects of horseback riding on the balance improvement of the children with cerebral palsy. Incheon University, Dissertation of master's degree, 2003.

12) Back JH, Sung BJ, Lee BW: The analysis of electromyogram in horse riding stimulator. Journal of Sport and Leisure Studies, 2005, 23: 341-352.

13) Lee SK, Jeong JH: The effects of indoor horseback-riding exercise on health-related fitness, serum lipids, and defecation satisfaction of female collegiate students. Korea Sport Research, 2005, 16: 153-160.

14) Cho WS, Kim YN, Park JS, et al.: The effects of ability to balance posture and proprioception by horse riding simulator and galvanic vestibular stimulation. Phys Ther Kor, 2012, 19: 39-47. [CrossRef]

15) Kuczyński M, Słonka K: Influence of artificial saddle riding on postural stability in children with cerebral palsy. Gait Posture, 1999, 10: 154-160. [Medline] [CrossRef]

16) Hammer A, Nilsagård $Y$, Forsberg A, et al.: Evaluation of therapeutic riding (Sweden)/hippotherapy (United States). A single-subject experimental design study replicated in eleven patients with multiple sclerosis. Physiother Theory Pract, 2005, 21: 51-77. [Medline] [CrossRef]

17) Beinotti F, Correia N, Christofoletti G, et al.: Use of hippotherapy in gait training for hemiparetic post-stroke. Arq Neuropsiquiatr, 2010, 68: 908913. [Medline] [CrossRef]

18) Nashner LM, Peters JF: Dynamic posturography in the diagnosis and management of dizziness and balance disorders. Neurol Clin, 1990, 8: 331-349. [Medline] 